\title{
The Enlightenment of SPOC on Teaching Reform of Higher Education in China_Based on the Perspective of Mastery Learning Theory
}

\author{
Jian-yong Lou, Pei-rong Zheng, Chen Jiang \\ College of Education and Science Technology, Zhejiang University of Technology, Hangzhou, China \\ Email address: \\ 8968096591@189.cn (Jian-yong Lou), 421294353@qq.com (Pei-rong Zheng)
}

\section{To cite this article:}

Jian-yong Lou, Pei-rong Zheng, Chen Jiang. The Enlightenment of SPOC on Teaching Reform of Higher Education in China_-Based on the Perspective of Mastery Learning Theory. Science Journal of Education. Vol. 4, No. 2, 2016, pp. 95-100. doi: 10.11648/j.sjedu.20160402.22

Received: March 21, 2016; Accepted: April 12, 2016; Published: May 19, 2016

\begin{abstract}
SPOC is not only a MOOC supplement but also the product of MOOC and traditional teaching method's integration innovation, which cause the extensive concern of the global education. This article starts with mastering advanced concepts and the basic process of mastery learning theory, followed by a deep analysisof SPOC through mastery learning theory, and finally put forwards enlightenment on teaching reform of higher education in China from SPOC.
\end{abstract}

Keywords: Flipping Classroom, Blending Learning, Mastery Learning, Teaching Effect

\section{Introduction}

As a new generation of revolution of network learning, MOOC get numerous people over the world involved in it. It sets off a burst of spring breeze in education and various researches followed by also have mushroomed and thrived. However, after a period of research and development, MOOC has also exposed some disadvantages, such as the disharmony between curriculum design and students, the lack of effective supervision in the teaching process and the aimless teaching mode. Under such a background, SPOC arises at the historic moment. Professor Robert Lue, a famous scholar of Harvard University, said SPOC will replace MOOC - 1.0 version of the online education and move towards post -MOOC era [1]. Many scholars have also pointed out that MOOC should change into a classroom teaching tool and enter the SPOC era to make the traditional mode change the model of traditional classroom into online learning.

Western countries have done earlier researches on SPOC, which came up when studying and improving MOOC. After searching on Google scholar and EBSC, we found most researchers focusing on SPOC are from universities. As for research themes, most of them focus on comtrastive study with MOOC and some are comparative study based on application cases of SPOC in universities while researches about learning theory, teaching design and methods and the influence of SPOC on higher eduction have received little attention [2]. Some top universitieis in the world such as Havard University, University of California, Berkeley, and Massachusetts Institute of Technology are carrying out further research and experiments and have made great achievements both theoretically and practically [3]. Chinese online education hasn't developed as fast as that abroad, thus most teaching models and experiments are learned abroad. Most Chinese research on SPOC pay attention to its baisc concept, theoretial basi, teaching features, significance and teaching advantages. Besides, introduction to oversea cases, technology application, resource development also gainmuch spotlight.

As an advanced mixed course teaching model, SPOC is still at an early stage in China. Most research are based on MOOC and lack analysis of the reasonability and advantages of SPOC from pedagogical and psychological perspectives. This article is based on Benjamin Bloom's mastering learning theory and makes an intensive study of SPOC, laying a theoretical fundation for further study.

\section{The Concept and Development of SPOC}

SPOC is short for "Small Private Online Course", Chinese translated as "small-scale Private Online course", it is called 
"flip classroom" or "Private class" It is a new hybrid courses patterns bred in the process of applying MOOC better to blended learning [4]. It makes up for the MOOC defects in teaching and brings the innovative online education experience. SPOC's core idea is that in the traditional enclosed school classroom, on-demanding and reasonably use MOOC video and even its matched online communication, evaluation and feedback function to carry out the student-centered teaching to create the combination of traditional classroom teaching and online teaching blended learning mode, namely to flipped classroom. SPOC as MOOC's innovation under the perspective of blended learning, it has great difference with MOOC on the teaching strategy and object oriented. However, there is no essential difference between them on the part of online learning's implementation and platform technology. In fact, "Small" and "Private" of SPOC are related to "Massive" and "Open" in the MOOC. Among them the meaning of "Small" is Minority or Small scale, refers to the number of people learning, generally in dozens to hundreds of people. The meaning of "Private" refers to restriction of learners, only applicants who can meet the standards can enter the SPOC course." Online" is in the internet, mainly refers to make network transmission through the Internet technology. It is important to emphasize that to ensure the effective implementation of SPOC, one need to not only complete the MOOC needed high quality video, unitary knowledge, learning and management standardization, etc., but also have a teaching team whose members are knowledgeable, experienced and have the qualified computer skill. That is: contain flipping content, and be able to flip it. Anyway, SPOC is the fused model of MOOC and traditional classroom. Compared with MOOC, it effectively strengthens the guidance of the teacher; meanwhile, increases the mastery degree and the participation of students so as to enhance the quality of student learning. [5]

Armando Fox and David Patterson, leaders of MOOC at the University of California, proposed SPOC based on original research of MOOC. At present, some famous colleges and universities are in the research of SPOC and experiment teaching mode. Prominent colleges are Berkeley, Harvard, and MIT etc. Being an educator of the world, many universities in China began to actively try this new curriculum pattern different from the traditional classroom. The leader among them is the Tsinghua University Press. It was the first of creating course platform "Zhixuyuan" then introduced the related courses, and at the same time provided matching teaching resources. The first course is launched at the SPOC platform in September 2013, thus SPOC started the journey in China.

After summarizing those SPOC attempts in real classes, it is not difficult to find that the current form of SPOC for students is the blending teaching model of combining traditional classroom with online class. In generally, Course in a campus is using the MOOC video as a teaching resource and form to flip the classroom teaching. The basic process is that teacher assigns the related video materials as homework or preview materials for students, then answers students' questions in classroom, let students communicate and discuss. By doing so, teacher would know how well students understand about knowledge and where their interest lays to, and solve problems and consolidate knowledge together with the students in the classroom. In general, the teacher can set up the course content according to their own preferences and requirements, and rationally regulate courses progress and evaluation index.

\section{Understanding the "Mastery Learning"}

The "Mastery Learning" is supporting teaching theory behind SPOC (Small Private Online Course). It combines the teaching and learning ingeniously, and with optimism color, "Mastery Learning" is a teaching form effectively combined individual teaching and collective teaching. The "Mastery Learning" is emerged in late 1960s; the representative of it is Bloom who is famous as an educationalist and psychologist. His teaching theory consists of three parts - the "Taxonomy of Educational Objectives", the "Mastery Learning" theory and the educational evaluation theory. In these theories, the "Mastery Learning" is the essence of teaching research [6].

\subsection{The Basic Idea of "Mastery Learning”}

The key of the "Mastery Learning" is that students' learning outcome cannot be determined directly by their learning abilities which only decides learning time they need to get same learning targets". In other words, with scientific and reasonable learning materials, if students have enough learning time they need and proper help in teaching, most of them can finish the required learning targets. The main strategy of "Mastery Learning" is taking the difference between different learners' learning abilities as the preliminary basis, its teaching method if collective learning method and its teaching aims is a new teaching strategy-- to make every student can learn well, get an advantage on class teaching at the same time, and eliminate poor students in traditional class teaching. This strategy can be explained by constructionism psychology that the main reason why many learners cannot get good learning effects is they didn't get enough learning time depending on individual needs and proper help in teaching. This "Mastery Learning" theory has a positive and profound impact on improving teaching methods and teaching process, fully mobilizing learners' motivation and learning abilities, and improving teaching quality at all aspects.

\section{2. “Mastery Learning” Teaching Process}

In the preparation stage, the first to believe is that we can grasp. Then, determine the teaching learning content, objectives and measurement and evaluation tools. Next, develop lesson plans, teaching unit contains the schema, clear and specific to each unit of mastery goal, according to the teaching objectives of the unit to develop the appropriate form of tests, designed to aid the correct tools and spare teaching 
materials for learners choose to use teaching resources when they encounter problems and difficulties in the learning process. What's more, the general in the implementation of "mastery learning" before the need for diagnostic evaluation.

During the implementation phase of teaching, according to the following three steps sequentially advance: first to grasp the orientation (to introduce the learner to master the common process of learning to enable students to understand this method). Then, carry out the systematic teaching. Teachers in the classroom learning to real-time evaluation of the situation and adjust the teaching schedule as appropriate. Next, have test. Note that the proposition cannot be free, to use good form of pre-scheduled test questions. After corrected, did not pass the test to students according to their test revealed the problem to supplement teaching, providing opportunities for them to learn again. It is need to conduct a re-test after the correction to the feedback correction results. Finally, in order to grasp and carry out grading. After learning all the learning contents, take summative tests for all students, the end of the round as a learning assessment. It is worth emphasizing that the final assessment of learning to master the only "master" and "did not grasp" In both cases, do not look learners in the class in which the ranking.

\section{4. "Mastery Learning" Under the Perspective of SPOC}

"Mastery learning" research foundation and Carroll's "school model" are closely related. "School mode" that opportunity, perseverance, teaching quality, student comprehension and aptitude of these five variables that can affect the interaction of teaching. Teaching effectiveness is the amount of time learners learning actually used and the amount of time to master the learning content required for a function, that is the learning effect $=$ (the actual amount of time for the amount of time to learn / need). To ensure that students would get a deeper level of learning, teachers should actually increase the amount of time learners for learning, while reducing the amount of time required for learners to grasp. Putting these variables and the relationship between them a good control, teacher could have achieved a combined positive effect on teaching. As shown from the perspective of these five variables we used to analyze the effectiveness of SPOC teaching, and teaching principles from the perspective to reflect SPOC design.

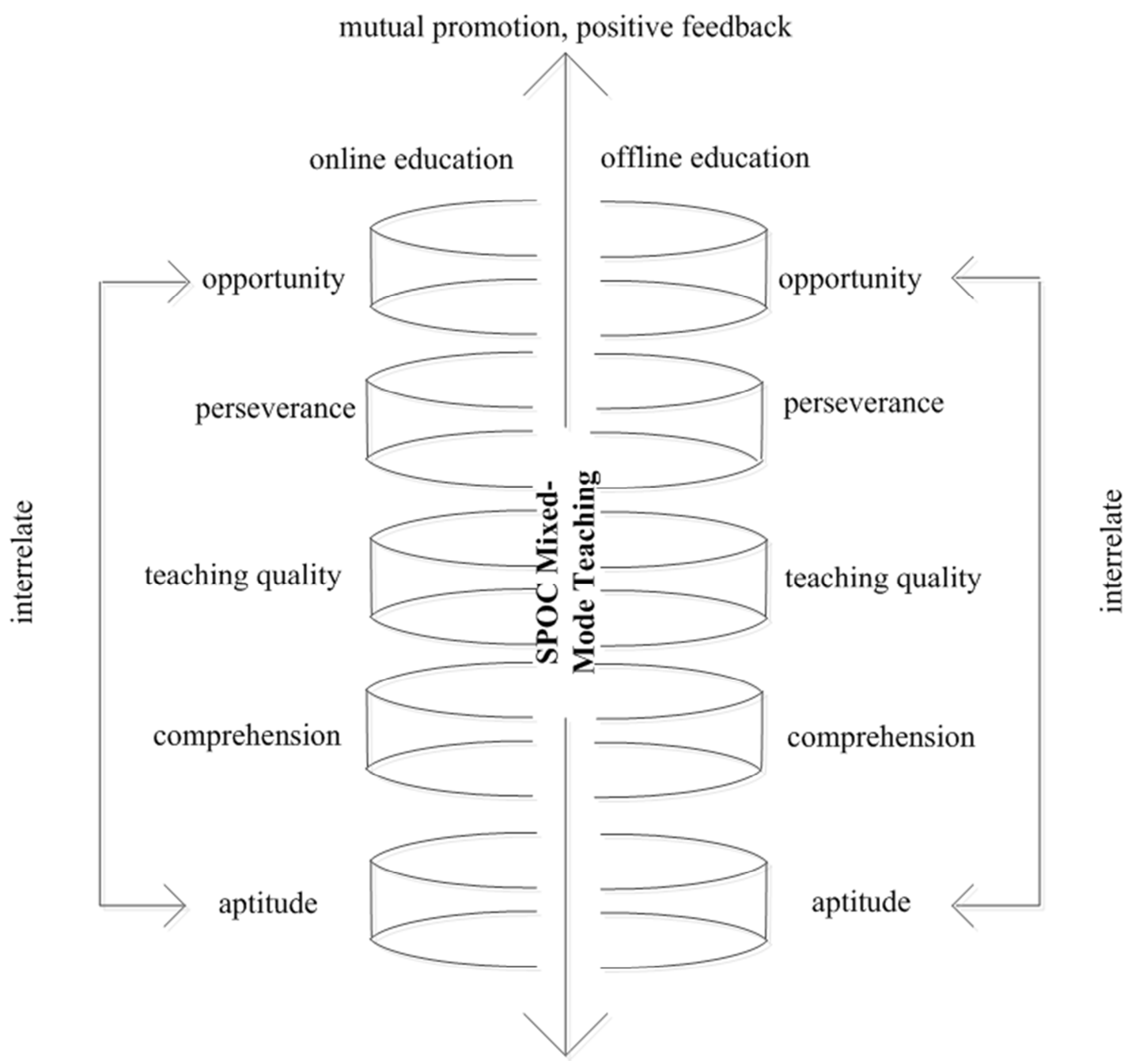

Figure 1. Five major factors infect SPOC blending teaching model. 


\subsection{Variable One: Opportunity}

Opportunity refers to the clearly defined period of time that learners need to achieve learning objectives. Bloom believes that if learners have sufficient time to study, almost all students can achieve mastery level. For this reason, he believes teachers should do: 1 . find ways to provide each learner a manner consistent with their level of learning time required. 2. Change the time to learn as much as some of the learners need. SPOC as a hybrid teaching model, the front part of the video in the form of lectures MOOC provides essential condition for students with various intelligence. In the early MOOC video lectures, the course can be repeated many times through playing the video, even some key parts of it; and student would be able to practice several times when repeating the video. Since the early learners got the basic understanding from the video lessons, the utilization of the class teaching time will be increased significantly, the time required for traditional classroom will be reduced. Therefore, SPOC teaching can effectively increase the "opportunity."

\subsection{Variable Two: Perseverance}

The so-called perseverance, refers to the time learner willing to spend on learning, which is closely related to the learner's own interest in learning and learning attitude. However, educational psychology theories and research shows that, if the learner, in the learning process, gain experience reward or success without interruption, then he is willing to cast more time for learning tasks. On the contrary, if he had been punished or experienced failure, he is likely to reduce their investment in learning time. From this perspective, SPOC, in a sense, effectively reduce the burden learners carry and help learners continuingly obtain accomplishment in learning through its fragmented learning curriculum design and sequence video. In addition, SPOC fully uses immediate feedback from exercises and operations issues, which allows students to get immediate and effective encouragement, enhance the interest of students and indirectly increase the amount of time students spent in learning. In addition, SPOC's flipped classroom model allows students to have more opportunities to communicate in the classroom, to learn to express their ideas and experience, to increase interest in learning. Therefore, SPOC hybrid teaching model also can be effective for learners "perseverance" to inject fresh blood.

\subsection{Variable Three: Teaching Quality}

This variable refers to presentation and explanation of various elements in teaching, as well as their order of appearance, it reflects the matching of teaching and student's learning situation. Bloom believes education must have the following elements: Teachers should provide clues or give guidance for learners, learners' participation in learning activities; teachers provide appropriate reinforcement to attract learners, as well as immediate and effective feedback correction system. During the learning process different learners have their own cognitive structure and cognitive style, thus they have different learning needs, and requires different assistant. Therefore, teachers need to address the different needs of learners with different learning cues, and give the corresponding instructions, which makes "one-to-one guidance" teaching valid. Based on this perspective, it is not difficult to find a good SPOC program which can actually help learners with their own actual situation to carry out self-paced learning. This custom not only embodies in free to choose what to study by the learners, also determines their order of learning. SPOC's flipped classroom model is actually a customized learning assistance; it can provide different feedback or tips for different students. In the latter part of the classroom, with early knowledge base, students' participations in classroom activities would certainly have a leap in terms of quality and quantities [7]. In addition, the use of pre-SPOC MOOC learning courses for instant statistical data and visual rendering, these data support the teachers and the teaching guide provides the appropriate reference and help, so that the feedback correction - the system more scientific and perfect. In conclusion, SPOC teaching can help teachers create a more scientific instructional design and high quality teaching services, so the learning efficiency has been improved to a large extent.

\subsection{Variable Four: Comprehension}

In Bloom's view, if the student teacher to explain the contents of the textbook understanding or not thorough or biased, then he in the learning process easy difficulty. Therefore, teachers in teaching should be flexible in using a variety of teaching and learning activities and teaching methods to help each learner to understand what they learn, and in this process continue to develop its ability to understand. With consistent teaching SPOC is a distinctive feature is the ability to support a flexible combination of a variety of teaching activities and the formation of scientific learning sequences, and these sequences are related to specific learning goals correspond. SPOC during curriculum design, teacher is based on specific learning objectives designed to achieve a form to promote students' understanding of "activities sequence. Principle here is to promote student understanding through its complete grasp and thus reduce learning time required.

From the status quo of Higher Education in China, the current majority of schools carry out class-based teaching system, a teacher in the face of dozens of students even more. If some of the students understand the capacity is weak, then it will have difficulty learning that often cannot keep up the rhythm of teaching. So the improvement of teaching, such as by individual treatment, group cooperation and exchange, explain vivid textbook, using multi-sensory approach to mobilize and game-based learning and other teaching to enable each student to enhance and develop their ability to understand teaching The SPOC being able to classroom teachers in the limited time and energy, so that the actual classroom to have more than a rich series of teaching provided the opportunity [8]. 


\subsection{Variable Five: Aptitude}

The so-called Aptitude simply means that learners' efficiency, such as the writing speed, reading the depth, etc., that learners master a certain amount of time needed to learn the material. We want to significantly enhance the ability to know that it is more difficult, because we often only one semester courses or a year, for our long learning career is very short. Then take another perspective, if given adequate learning time learner - given enough "opportunity", then most of the learners to achieve certain learning goals. In fact, aptitude learner only indicates the speed, and do not indicate the level of learning they may achieve. This variable is an "opportunity" related, apparently SPOC good solution to this problem. In addition, there is evidence that environmental conditions by providing appropriate and relevant learning experience, it can change a student's aptitude. Especially for SPOC study, many learners may not adapt to the mixed teaching mode, teachers recommend learning strategies can help learners to grasp how to learn more efficiently, but also effectively reduce the time required for their learning.

In short, with the support of SPOC teaching related technology to easily achieve mastery learning teaching principles, not only can increase performance in time according to the needs of learners and students to acquire the necessary knowledge to effectively reduce the time and can easily provide learning sequence and timely guidance to assist students to achieve mastery of. Knowledge and skills to master is learning to master teaching theory emphasized, and blended teaching model SPOC may be well with the completion of these two aspects. Early MOOC video can help students get promoted at the level of knowledge, classroom discussion and guidance is able to carry out the latter part of the development of skills and abilities in the consolidation on the basis of knowledge. More importantly, in order to develop students' higher-order thinking ability, SPOC online learning courses students learning ability and self-planning ability, classroom learning and the exchange of online under more integration of the social constructivist theory and Peer Tutoring Teaching Method principle, can effectively improve students' overall literacy.

\section{Inspiration of Higher Education Reform in China from SPOC}

In the age of the big data, profound reform of education is inevitable across nations. In the case of US quarter system, an academic year is divided into four semesters. Due to the limitation of time, teaching contents could not be covered in one semester. The common solution is reasonably split one course into two consecutive courses and held separately in two semesters. The emphasis of semester one is specifically identifying learning task. Semester two is utilized to focus on project design and participation [9]. Though semester one contains less exercises, the value of it is material. Semester one can be conducted through MOOC video at the front section of SPOC. Training academic skills in semester two is processed through latter section of SPOC. Comparing with traditional class, Flipping Classroom in SPOC have certain advantages and value, which efficiently offsets the weakness of MOOC unable to offering equivalent teaching experience like traditional class.

In the case of China, the current circumstance in China is two semesters in an academic year. The contents between two semesters tend to be irrelevant, and students less likely obtain sufficient training through self-study and practice. It is common that teaching staff tends to adopt textbook as the sole source of teaching material, and use same PowerPoint Slides over years, even the final examination. It is no surprise that neither teaching staff nor student would have enthusiasm in such circumstance. The ex-undersecretary from Ministry of Education of the People's Republic of China, China Association of Higher Education President, Yuanqing Zhou emphasized that "A revolution needs to be done regarding the college education methodology; College education quality is out of topic, only after transformation of student-oriented college education is realized." on the theme report of "There are "four classics" needs to be revised repeatedly for fully promoting education quality" [10]. The truth of higher education status in China is that colleges remaining focus on training "obedient" students; and teaching material in class is still theory based. The pattern of unidirectional lecturing from classroom, and classroom only, makes student nerd and copy machine. It limits students' viability and initiative, makes them "notes copying machines". Students lost the ability of independent thinking and imaging. They will be unable to question or interact.

It is worth thinking about student oriented hybrid teaching mode from SPOC [11]. Based on SPOC's teaching mode, college teaching staff could start with bringing advance discussion into classroom and left the basic knowledge after class. To be specific, teacher could ask student to take MOOC class before the lecture. Student would be more concentrated on creative videos on MOOC. They could adjust their study progress based on their capability, repeat playing videos and make a pause when they need to. Student would be more initiative to learn from MOOC when they could encourage and compete with others through MOOC's peer evaluation platform. One step further teacher could hold group discussion to exchange self-study experience or respond to students' doubts, since they no longer needs class time for teaching basic knowledge [12].

\section{Summary and Future Prospects}

This study enriches the SPOC connotations and applies it into the theory of higher education. It provides a new idea for higher education curriculum reform. Currently, explorations of higher education teaching methods and curriculum model are in a traditional direction. It lacks fresh blood. This study is based on the Broome mastery learning teaching theory, it analyzes the SPOC teaching philosophy and basic processes, which is a new hybrid curriculum model, and also analyzes its scientific and advanced places. This is the application of 
SPOC in higher education, and it has laid a theoretical foundation and research directions for it.

The booming and spreading of MOOC and SPOC are challenges and opportunities for China's education. During the educational reform, China's college education should actively imitate advanced idea in SPOC; emphasis on researching and reforming talents training ideas and teaching methodology; and follow the global education revolution pace, keep abreast of the times.

\section{References}

[1] Ye-qin Kang. The New Age of Online Education - SPOC [J]. Institute of Education Tsinghua University, 2014, (35): 85-93.

[2] Fox, A. Patterson, D. A. \& Ilson, R. et al. (2014). Software Engineering Curriculum Technology Transfer: Lessons Learned from MOOCs and SPOCs [R]. UC Berkeley Technical Report.

[3] Ran Chen, Yang Cheng. SPOC Blended Learning Model Design [J]. Distance Education in China, 2015 (05): 15-16.

[4] Jing-feng Shen, Yun-xia Shi, Fang-mei Lv. Educational Reform of Design Methodology under SPOC [J]. Education Teaching Forum, 2015, (01): 260-261.

[5] Jon Baggaley. Reflection MOOC Postscript [J]. Distance Education, 2014 (35): 126-132.
[6] Zhen-guo Yuan. Contemporary Education [M]. Educational Science Publishing House, 2005.

[7] Xin Guan. From "Bublic Benefit" to "Private Tailor"- Research of the Development from MOOC to SPOC [J]. Library Work In Colleges and Universties, 2015, 35 (165): 19-21.

[8] Yong-lin Zhang. SPOC: Depth MOOC integration with Campus [J]. Chinese Vocational and Technical Education Chinese Education, 2015 (18): 14-18.

[9] Wei Xu, Yong-zheng Jia, Armando Fox, David Patterson. From MOOC to SPOC --- Academic Conversation Based on MOOC Practice in University of California Berkeley and Tsinghua University [J]. Modern Distance Education Research, 2014, (4): $13-22$.

[10] Jun-chao Zhang. Push Forward With the Education Reform From "Teach" to "Learn" [J]. Journal of Higher Education, 2012, (08): 104-109.

[11] De-guang Yang. 10 Problems China's College Education faces after entering public education [J]. Journal of Shanghai Normal University (Philosophy \& Social Science Edition), 2011, (03): 44-58.

[12] Jing-ru Ge. Enlightment from MOOC to Higher Professional Education Development in China $[\mathrm{J}]$. Market Weekly (Theoretical Research), 2014, (11): 118-119. 